\title{
Amount of solution drunk is a factor in the establishment of taste aversion
}

\author{
NIGEL BOND and EROS DI GIUSTO \\ School of Behavioural Sciences, Macquarie University, North Ryde, N. S. W. 2113, Australia
}

\begin{abstract}
Experiment 1 demonstrated that the strength of a rat's aversion to saccharin is a direct function of the amount of saccharin it consumed prior to poisoning. Using Kalat and Rozin's (1973) procedure, Experiment II showed that results consistent with a "learned-safety" theory of taste aversion appear to depend on whether rats drink most saccharin on their first or second exposure to the solution prior to poisoning. Experiment III demonstrated that when animals drank equal amounts of saccharin solution on each of two exposures prior to poisoning, evidence strongly confirming the "learned-safety" theory was obtained. These experiments together demonstrate the importance of amount of solution drunk in the determination of taste aversion.
\end{abstract}

A number of studies have shown that rats will learn to avoid a flavored solution if their initial exposure to that solution is associated with poisoning (e.g., Revusky \& Garcia, 1970). This finding is of special interest because it demonstrates the ability of rats to learn an association, despite delays of up to $12 \mathrm{~h}$ between the CS (taste) and the US (poisoning), even when only a single trial is employed (Smith \& Roll, 1967).

Several studies have investigated the effects of a variety of CS parameters on the strength of conditioned taste aversions. For example, Dragoin (1971) has shown that taste-aversion learning varies directly with the concentration of solution drunk when $\mathrm{HCl}$ is used, and Revusky and Bedarf (1967) have demonstrated that exposure to the CS prior to conditioning reduces the degree of subsequent taste-aversion learning.

Surprisingly, Smith and Morris (1963) provide the only study specifically investigating the effect of amount of CS on the strength of taste-aversion learning. Smith and Morris found that the amount of saccharin consumed prior to X-radiation had no effect on the size of the subsequent aversion. The generalizability of these results is questionable, however, since it is possible that the range of amounts consumed (4.6-9.2 $\mathrm{g}$ saccharin solution) was not sufficient to produce differential results. In addition, all the values of X-radiation used may have been sufficiently large to produce maximal degrees of aversion over all levels of saccharin consumption. The latter is suggested by the finding in the Smith and Morris (1963) study that a wide range of $\mathrm{X}$-radiation doses $(50 \mathrm{r}$ to $350 \mathrm{r})$ did not lead to significant differences in taste aversion.

The first experiment investigated the effects of amount of saccharin solution drunk prior to poisoning on taste-aversion learning. In order to minimize the possibility of floor effects, a long CS-US delay period

The authors wish to thank E. Backhouse, W. Harland, and D. Hollely for their valuable technical assistance and Professor $P$. van Sommers for his comments on an earlier version of the manuscript. Reprints may be obtained from Nigel Bond. was used in conjunction with an appropriately regulated dose of lithium chloride, and a one-bottle test was employed.

\section{EXPERIMENT I}

\section{Method}

In all the experiments to be reported, male Wistar rats were used. The animals were housed in pairs in wire cages (15 $\times 24 \times 20 \mathrm{~cm}$ high) with free access to food for the duration of the experiment. Subjects were given access to water in separate drinking cages. The drinking cages were similar in dimensions to the home cages, but differed in that a $50-\mathrm{ml}$ graduated Richter tube could be inserted in the front of the cage. No food was available in the drinking cages. Prior to each experiment, individual subjects were given access to tap water for $10 \mathrm{~min}$ per day for 7 consecutive days.

Thirty-four experimentally naive subjects were used in Experiment I. They were 80 days old at the beginning of the experiment and were assigned randomly to one of the three treatment groups (see Table 1 for experimental design).

On Day 1 (conditioning day) a tube was inserted into the drinking cage containing either water or a $.25 \%$ solution of saccharin and the animal was allowed to consume $4.0 \mathrm{ml}$. The first tube was then removed, and a second tube was inserted from which the animal was allowed to consume $1.0 \mathrm{ml}$ of fluid. Finally, the second tube was removed, a third inserted, and the animal was allowed to consume a further $.5 \mathrm{ml}$ of fluid.

Thus, all three groups drank $5.5 \mathrm{ml}$ of fluid but differed in the amount of saccharin they were allowed to consume. The first group received $5.5 \mathrm{ml}$, the second $1.5 \mathrm{ml}$, and the third $.5 \mathrm{ml}$. Three hours later, each rat was injected intraperitoneally with $10 \mathrm{ml} / \mathrm{kg}$ of $.3 \mathrm{M}$ lithium chloride. Days 2 and 3 served as recovery days, each subject being given access to water for $10 \mathrm{~min} / \mathrm{day}$. On Day 4 (test day), the rats were given access to saccharin for $30 \mathrm{~min}$, and the amount consumed was recorded.

Table 1

Amount and Type of Fluid Consumed at Each Exposure for Experiment I $(S=$ Saccharin, $W=$ Water $)$

\begin{tabular}{ccccc} 
& & \multicolumn{3}{c}{ Group } \\
\cline { 3 - 5 } $\begin{array}{c}\text { Expo- } \\
\text { sure }\end{array}$ & $\begin{array}{c}\text { Amount } \\
(\mathrm{ml})\end{array}$ & $5.5 \mathrm{mlS}$ & $1.5 \mathrm{mlS}$ & $.5 \mathrm{mlS}$ \\
\hline 1 & 4.0 & $\mathrm{~S}$ & $\mathrm{~W}$ & $\mathrm{~W}$ \\
2 & 1.0 & $\mathrm{~S}$ & $\mathrm{~S}$ & $\mathrm{~W}$ \\
3 & .5 & $\mathrm{~S}$ & $\mathrm{~S}$ & $\mathrm{~S}$ \\
\hline
\end{tabular}




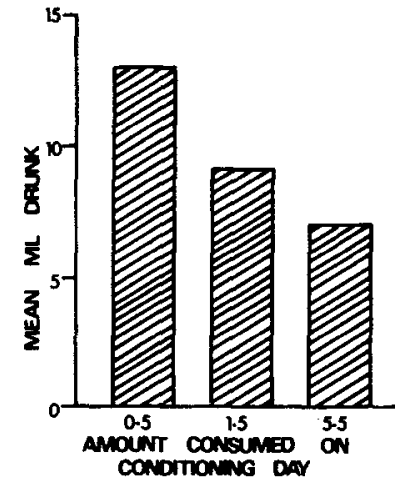

Figure 1. Results of Experiment I.

\section{Results and Discussion}

Results are shown in Figure 1. In this and subsequent experiments, Mann-Whitney U tests (two-tailed) were used to analyze the data.

The group which drank $5.5 \mathrm{ml}$ of saccharin on the conditioning day acquired a stronger aversion than either the $1.5-\mathrm{ml}$ group $(\mathrm{p}<.02)$ or the $.5-\mathrm{ml}$ group $(\mathrm{p}<.002)$. The $1.5-\mathrm{ml}$ group acquired a stronger aversion than the $.5-\mathrm{ml}$ group $(p<.02)$. These results suggest that the strength of an animal's aversion to saccharin is a direct function of the amount of saccharin it consumed prior to poisoning.

\section{EXPERIMENT II}

In the previous experiment, amount of saccharin solution drunk was shown to be a significant determinant of the strength of the conditioned taste aversion. This finding is of relevance to a recent important paper by Kalat and Rozin (1973). They found that if a rat drinks the same solution twice within the effective CS-US interval before a single poisoning, it learns less aversion than if it received only the second presentation. This finding is consistent with their "learned-safety" theory of taste-aversion learning but is incompatible with interference or decay theories of the phenomenon. In their study, Kalat and Rozin allowed the subjects 10 min exposure to the solution when it was first presented, and $2.5 \mathrm{~min}$ exposure on the second presentation. In view of the decreased exposure time on the second presentation and the fact that the subjects were less deprived as a result of the first exposure, it is possible that the subjects drank unequal amounts of solution on the two occasions. This is also true of the replication of the Kalat and Rozin study by Bolles, Riley, and Laskowski (1973). In a replication of the Kalat and Rozin (1973) experiment in our own laboratory, we have found that subjects in fact drink significantly less on the second occasion. As a result of the different amounts drunk on the two occasions, it is conceivable that results supporting a "learned-safety" theory of taste aversion might depend on whether the appropriate subjects drank most on the first or on the
Table 2

Time Prior to Injection that Each Solution Was Presented for Both Subexperiments of Experiment II ( $S=$ Saccharin, $W=$ Water $)$

\begin{tabular}{|c|c|c|c|}
\hline $\begin{array}{l}\text { Time Prior } \\
\text { to Injec- } \\
\text { tion }\end{array}$ & & xperim & \\
\hline $\begin{array}{l}4 \mathrm{~h} \\
1 / 2 \mathrm{~h}\end{array}$ & $\begin{array}{l}4.5 \mathrm{~S} \\
1.5 \mathrm{~S}\end{array}$ & $\begin{array}{l}4.5 \mathrm{~S} \\
1.5 \mathrm{~W}\end{array}$ & $\begin{array}{l}4.5 \mathrm{~W} \\
1.5 \mathrm{~S}\end{array}$ \\
\hline & & xperim & \\
\hline $\begin{array}{l}4 \mathrm{~h} \\
1 / 2 \mathrm{~h}\end{array}$ & $\begin{array}{l}1.5 \mathrm{~S} \\
4.5 \mathrm{~S}\end{array}$ & $\begin{array}{l}1.5 \mathrm{~S} \\
4.5 \mathrm{~W}\end{array}$ & $\begin{array}{l}1.5 \mathrm{~W} \\
4.5 \mathrm{~S}\end{array}$ \\
\hline
\end{tabular}

second exposure to the same solution. In the present experiment, this possibility was tested by allowing subjects to drink the larger amount of saccharin solution on either the first or the second exposure.

\section{Method}

Seventy-two experimentally naive subjects were used in Experiment II. They were 60 days old at the beginning of the experiment.

On Day 1 (conditioning day) the animals were divided into six groups of 12 subjects each and were subjected to the treatments illustrated in Table 2. The fluids used were water and a $.25 \%$ saccharin solution. All subjects received two presentations of fluid amounting to $6.0 \mathrm{ml}$, the first presentation being $4 \mathrm{~h}$ prior to poisoning, the second $1 / 2 \mathrm{~h}$ prior to poisoning. Poisoning consisted of the intraperitoneal injection of $10 \mathrm{ml} / \mathrm{kg}$ of $.3 \mathrm{M}$ lithium chloride. Days 2 and 3 served as recovery days, each subject being given access to water for $10 \mathrm{~min} /$ day. On Day 4 (test day), the rats were given access to saccharin for $30 \mathrm{~min}$ and the amount consumed was recorded

\section{Results}

Results are shown in Figure 2. Assuming that the $1 / 2-h$ groups are significantly different from the 4-h groups, interest centers on the performance of the groups which received saccharin at both times on the conditioning day. According to the "learned-safety" theory, they should both display less aversion than the groups which

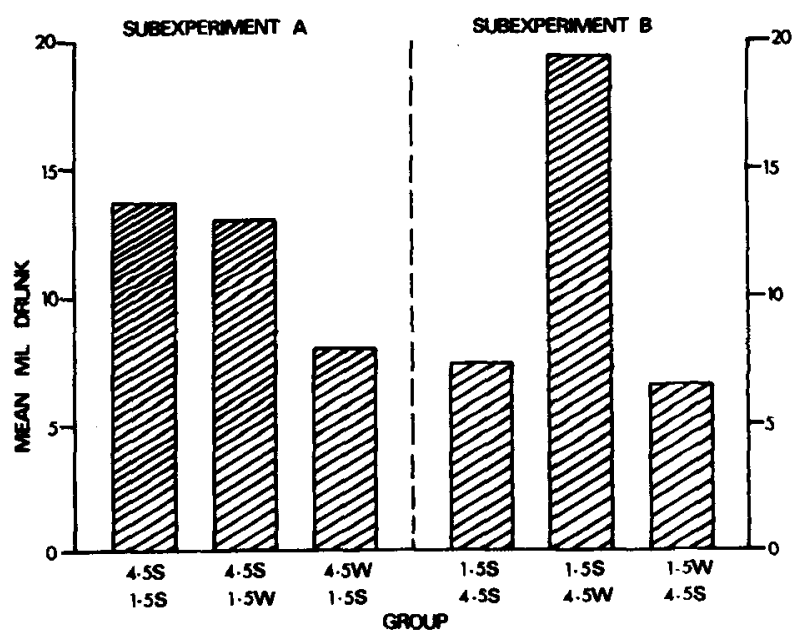

Figure 2. Results of Experiment II. 
received saccharin $1 / 2 \mathrm{~h}$ before poisoning and possibly as little aversion as the groups which received saccharin $4 \mathrm{~h}$ before poisoning.

Subexperiment A. As expected, the $1 / 2-\mathrm{h}$ group learned a stronger aversion than the $4 . h$ group $(4.5 \mathrm{~W}-1.5 \mathrm{~S}$, $4.5 \mathrm{~S}-1.5 \mathrm{~W} ; \mathrm{p}<.02)$. The group $(4.5 \mathrm{~S}-1.5 \mathrm{~S})$ receiving saccharin at both times on the conditioning day, learned a weaker aversion than the group $(4.5 \mathrm{~W}-1.5 \mathrm{~S})$ receiving $1.5 \mathrm{ml}$ of saccharin $1 / 2 \mathrm{~h}$ prior to poisoning $(\mathrm{p}<.02)$, and did not differ from the group $(4.5 \mathrm{~S}-1.5 \mathrm{~W})$ receiving $4.5 \mathrm{ml}$ of saccharin $4 \mathrm{~h}$ before poisoning $(p>1)$. The present pattern of results is consequently in agreement with the predictions of the "learned-safety" theory.

Subexperiment B. As in Subexperiment A, the $1 / 2-h$ group learned a stronger aversion than the 4 -h group $(1.5 \mathrm{~W}-4.5 \mathrm{~S}, 1.5 \mathrm{~S}-4.5 \mathrm{~W} ; \mathrm{p}<.002)$. However, in contrast to Subexperiment $A$, the group $(1.5 \mathrm{~S}-4.5 \mathrm{~S})$ receiving saccharin at both times did not differ from the group $(1.5 \mathrm{~W}-4.5 \mathrm{~S})$ receiving $4.5 \mathrm{ml}$ of saccharin $1 / 2 \mathrm{~h}$ prior to poisoning $(p>.1)$, but displayed a stronger aversion than the group $(1.5 \mathrm{~S}-4.5 \mathrm{~W})$ which received $1.5 \mathrm{ml}$ of saccharin $4 \mathrm{~h}$ before poisoning $(\mathrm{p}<.002)$. In the present case, the pattern of results demonstrates the absence of a "learned-safety" effect.

It is also interesting to note that the group which drank $1.5 \mathrm{ml}$ of saccharin $4 \mathrm{~h}$ before poisoning displayed a weaker aversion than the group which drank $4.5 \mathrm{ml}$ at this time $(1.5 \mathrm{~S}-4.5 \mathrm{~W} ; 4.5 \mathrm{~S}-1.5 \mathrm{~W} ; \mathrm{p}<.02)$. This finding again demonstrates that under certain circumstances the amount of saccharin consumed on the conditioning day is an important determinant of the animal's subsequent aversion. However, there was no difference in aversion between the groups receiving these differing amounts of saccharin $1 / 2 \mathrm{~h}$ before poisoning $(4.5 \mathrm{~W}-1.5 \mathrm{~S} ; 1.5 \mathrm{~W}-4.5 \mathrm{~S} ; \mathrm{p}>.1)$. This negative finding is possibly due to a floor effect, both groups learning such strong aversions that it was difficult to distinguish between them.

Further, as expected, the groups which drank saccharin once, $4 \mathrm{~h}$ prior to poisoning, acquired weaker aversions than the groups which drank an equal amount of saccharin once, $1 / 2 \mathrm{~h}$ before poisoning. This was true both for the groups which drank $4.5 \mathrm{ml}$ of saccharin $(4.5 \mathrm{~S}-1.5 \mathrm{~W}, 1.5 \mathrm{~W}-4.5 \mathrm{~S} ; \mathrm{p}<.002)$ and for the groups which drank $1.5 \mathrm{ml}$ of saccharin $(1.5 \mathrm{~S}-4.5 \mathrm{~W}$, $4.5 \mathrm{~W}-1.5 \mathrm{~S} ; \mathrm{p}<.002$ ).

\section{Discussion}

The results of Experiment II provide further evidence that amount of solution consumed is a potent variable in the determination of strength of learned taste aversions. More specifically, the study shows that differential results are obtained when one varies the amount of a solution drunk on each of two separate occasions prior to poisoning. If subjects are allowed to drink a greater quantity of solution on the first presentation than on the second, results consistent with the "learned-safety"
Table 3

Time Prior to Injection that Each Solution Was Presented in Experiment III (S = Saccharin, $W=$ Water $)$

\begin{tabular}{cccc}
\hline $\begin{array}{c}\text { Time Prior } \\
\text { to Injection }\end{array}$ & & Group & \\
\hline $4 \mathrm{~h}$ & $3.0 \mathrm{~S}$ & $3.0 \mathrm{~S}$ & $3.0 \mathrm{~W}$ \\
$1 / 2 \mathrm{~h}$ & $3.0 \mathrm{~S}$ & $3.0 \mathrm{~W}$ & $3.0 \mathrm{~S}$ \\
\hline
\end{tabular}

theory are obtained. If, however, subjects drink the larger quantity of solution on the second exposure, the "learned-safety" effect is minimized.1

In view of the ambiguity concerning the amounts consumed by subjects on each of the two exposures in the Kalat and Rozin (1973) study, the above findings suggest that a further test of the "learned-safety" theory with amounts explicitly controlled is warranted. In Experiment III, therefore, a further test of the theory was carried out by allowing subjects to drink exactly $3 \mathrm{ml}$ of saccharin solution on each of two exposures prior to poisoning.

\section{EXPERIMENT III}

\section{Method}

Thirty-six experimentally naive subjects were used in Experiment III. They were 60 days old at the beginning of the experiment.

On Day 1 (conditioning day) the animals were divided into three groups of 12 subjects each and subjected to the treatments illustrated in Table 3 . As in the previous experiments, the fluids used were water and a $.25 \%$ saccharin solution. Again, all subjects received two presentations of fluid totaling $6.0 \mathrm{ml}$, the first presentation $4 \mathrm{~h}$ prior to poisoning and the second $1 / 2 \mathrm{~h}$ prior to poisoning. Poisoning consisted of the intraperitoneal injection of $10 \mathrm{ml} / \mathrm{kg}$ of $.3 \mathrm{M}$ lithium chloride. Days 2 and 3 served as recovery days, each subject being given access to water for $10 \mathrm{~min} /$ day. On Day 4 (test day), the rats were given access to saccharin for $30 \mathrm{~min}$ and the amount consumed was recorded.

\section{Results and Discussion}

Results are shown in Figure 3 . The group ( $3 \mathrm{~W}-3 \mathrm{~S}$ ) consuming saccharin $1 / 2 \mathrm{~h}$ before poisoning learned a stronger aversion that the group $(3 \mathrm{~S}-3 \mathrm{~W})$ which consumed saccharin $4 \mathrm{~h}$ before poisoning $(\mathrm{p}<.002)$. The group ( $3 \mathrm{~S}-3 \mathrm{~S})$ consuming saccharin at both times on the conditioning day learned a weaker aversion than the $1 / 2$-h group $(p<.02)$ and did not differ from the 4-h group $(p>.10)$.

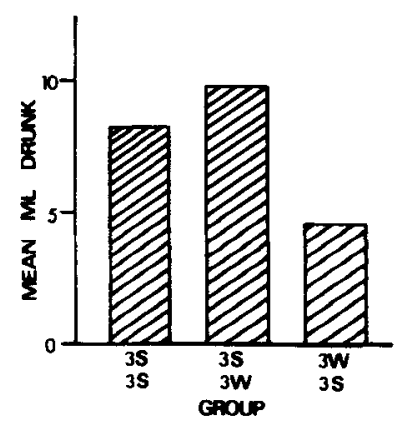

Figure 3. Results of Experiment III. 
The present results with amount controlled parallel exactly those obtained by Kalat and Rozin (1973) and thus confirm the "learned-safety" theory of taste-aversion learning.

\section{CONCLUSIONS}

The findings of Experiment I, unlike those of Smith and Morris (1963), demonstrate that amount of solution drunk is an important factor in the determination of strength of taste-aversion learning. In Experiment II it was shown that if an animal receives two presentations of the same solution, it will provide results supporting the "learned-safety" theory of taste aversion learning if allowed to drink more of the solution on the first presentation. However, if the subject is allowed to drink more of the solution on the second presentation, the "learned-safety" effect is eliminated. In Experiment III, where the subject was allowed to drink an equal amount of solution on each of the two successive presentations, results strongly supporting the "learned-safety" interpretation were obtained.

Additional findings from Experiment II suggest that the Kalat and Rozin (1973) "learned-safety" theory may need to be extended. Thus, rats which received $1.5 \mathrm{ml}$ saccharin $4 \mathrm{~h}$ prior to poisoning displayed a weaker aversion than rats which received $1.5 \mathrm{ml}$ saccharin $1 / 2 \mathrm{~h}$ prior to poisoning. However, rats which received $1.5 \mathrm{ml}$ saccharin followed by $4.5 \mathrm{ml}$ saccharin displayed a strong aversion. This finding suggests that subjects were able to "reassess safety" as a result of the increased amount of solution presented on the second occasion. Animals may, therefore, be capable of acquiring aversions to particular foods in a much more flexible manner than has so far been suggested.

\section{REFERENCES}

Bolles, R. C., Riley, A. L., \& Laskowski, B. A further demonstration of the learned safety effect in food aversion learning. Bulletin of the Psychonomic Society, 1973, 1, 190-192.

Domjan, M., \& Bowman, T. G. Learned safety and the CS-US delay gradient in taste-aversion learning. Learning and Motivation, $1974,5,409-423$.

Dragoin, $N$. B. Conditioning and extinction of taste aversions with variations in intensity of the CS and US in two strains of rats. Psychonomic Science, 1971, 22, 303-305.

Kalat, J. W., \& Rozin, P. "Learned-Safety" as a mechanism in long-delay taste-aversion learning in rats. Journal of Comparative and Physiological Psychology, 1973, 83, 198-207.

Revusky, S. H., \& Bedarf, E. W. Association of illness with prior ingestion of novel foods. Science, 1967, 155, 219-220.

Revusky, S. H., \& Garcia, J. Learned associations over long delays. In G. H. Bower and J. T. Spence (Eds.), The psychology of learning and motivation: Advances in research and theory Vol. 4. New York: Academic Press, 1970.

Smith, J. C., \& Morris, D. D. The use of X-rays as the unconditioned stimulus in five-hundred-day-old-rats. Journal of Comparative and Physiological Psychology, 1963, 56. 746-747.

Smith, J. C., \& Roll, D. L. Trace conditioning with X-rays as an aversive stimulus, Psychomic Science, 1967, 9, 11-12.

\section{NOTE}

1. Since completion of the present manuscript, Domjan and Bowman (1974) have also demonstrated that the "learned safety" effect is dependent on temporal parameters of fluid presentation.

(Received for publication July 17, 1974, accepted September $25,1974$. 